\title{
Does Temperament predict Emotional Intelligence?
}

\author{
Mary Rachelle Reyes-Wapano, $\mathrm{PhD}$ \\ Xavier University - Ateneo de Cagayan, Philippines
}

\begin{abstract}
This study examined the relationship between temperament and EI in an adolescent population. The sample of this study consisted of 300 respondents, 166(55\%) were females and $134(45 \%)$ were males. The average age of respondent's was19.10 years $(S D=1.956)$. Tools used in this study were Trait Meta Mood Scale -TMMS and Parental Authority Questionnaire - PAQ. Regression analyses were conducted to examine the predictive relationships among variables. Results revealed that parenting styles is a significant predict emotional intelligence among adolescents.. This study demonstrated that parenting styles contribute to EI development. The findings provide insight in the field of EI antecedents and underscore the potential significance of parents' role in the development EI among adolescents
\end{abstract}

Key words: emotional intelligence, parenting styles

\section{INTRODUCTION}

A mong adolescents, emotional intelligence is found to help reduce stress by decreasing conflict, improving relationships and understanding one's own emotions.

Studies have shown that emotional intelligence has a protective effect against suicidal ideation and attempts (Cha \& Nock, 2009; Abdolahhi \& Talib, 2015); against stress (Mikolajczak, Menil, Luminet, 2007; Davis and Humprey, 2012); and against depression (Cha \& Nock, 2009; FernandezBerrocal \& Extremera, 2016). Other studies reveal that emotional intelligence has a facilitative effect on overall health and life satisfaction (Urquijo, Extremera, \& Villa, 2016; Kong Zhao, \& You, 2012).

In light of the evidence in the literature on the prevalence of anxiety and depression in adolescents, (Boyd, Guilone, Kostanski, Ollendick, \& Shek, 2000 and on the potential of emotional intelligence to act as a protective factor against mental ill-health, this study is an attempt to investigate the role of temperament to the development of emotional intelligence

To date, there is a dearth of EI research that target Filipino adolescents. The few that focused on adolescent sample examined EI's association with academic achievement (Sta. Maria, 2007) and performance (Dinglasan, 2004; Manzano, 2004,). Most EI research in the Philippines that focused on adult respondents examined areas as job satisfaction (Asidao, 2001), job performance (Leano, 2006), leadership (Abdon, Farin, \& 2017). managerial skills (Galla, 2006), and decision-making styles (Natano, 2001). There is, then, a gap of knowledge on adolescent EI and its predictors.

This study then attempts to examine temperament, as predictor of emotional intelligence.
In this study, emotional intelligence is defined within the Mayer, Salovey and Caruso EI model (1999) which defines emotional intelligence as ability to "perceive emotions, to access and generate emotions so as to assist thought, to understand emotions and emotional meanings, and to reflectively regulate emotions to promote both better emotion and thought" (Mayer \& Salovey,1997, p. 5).

The multilevel investment model of emotional intelligence development (Zeidner, Matthews, \& Roberts, 2009) places the research question in context that relates to temperament as a determinant of adolescent emotional intelligence. This model of emotional intelligence development presents biological factors as probable causal influences on EI, as well as social-learning factors.

\section{EMOTIONAL INTELLIGENCE}

Mayer and Salovey (2004) describe emotion as one of three or four sets of mental operations. Motivation, identified as the first set of mental processes, is activated as a response to physical drive such as hunger, thirst or sexual needs, which directs organism to satisfy its survival needs. They further proposed that emotions seemed to evolve among mammalian species to point to actual or perceived changes in the environment and to elicit responses to a changing environment, whereas cognition allows the organism to solve problems and learn from its environment and includes learning, memory, and problem solving, information processing that is conscious and flexible (Mayer \& Salovey, 2004). The term emotional intelligence suggests the converging of emotion and cognition.From within this model, emotional intelligence is defined as: The capacity to reason about emotions, and of emotions to enhance thinking. It includes the abilities to accurately perceive emotions, to access and generate emotions so as to assist thought, to understand emotions and emotional knowledge, and to reflectively regulate emotions so as to promote emotional and intellectual growth (p. 197).

The mental ability model of Mayer and Salovey (2000) conceives of emotional intelligence as similar to other intelligences such as cognitive intelligence to the extent that it meets three empirical requirements. Mayer, Salovey and Caruso EI model (2000) enumerates these criteria: First, mental problems have definite correct and incorrect answers assessed by systematic scoring method; second, EI correlates with other measures of mental ability; and third, ability increases with age.

Multilevel Investment Model of Emotional Intelligence 
The multilevel investment model theorizes that the development of EI as depending on multiple levels of emotion-regulation process. It named temperament, rule-based skill acquisition, and self-aware emotion regulation as possible causes of individual differences in EI. With age, an individual's level of emotional competency progresses as the control of adaptation moves from biologically-based temperament to socially-learned self-directed emotion regulation. The model proposed three levels of control of behavior:

1. biology and temperament which is the first level of the model consisting of biologically based temperamental qualities and is thought to provide the foundation and structure of subsequent emotional development;

2. rule-based learning of emotional competencies is the second level of the model which involves the learning of emotional skills acquired through behavioural socialization strategies such as modelling of affective behaviours; and,

3. strategic emotion regulation development, the third level of the model whichcentres on the development of self-awareness and strategic regulation of emotional behaviours.

\section{TEMPERAMENT AND BIOLOGY OF EMOTIONAL INTELLIGENCE}

The investment model posits that emotional competencies are largely determined by the manner in which environmental factors interact with a person's biological constitution. Zeidner et al. (2009) proposed that the relationship between human biology and human behavior has been shown to be that of reciprocal determinism. Recent research by Halberstadt (as cited in Zeidner et al., 2009, p. 146) suggests that certain temperamental qualities may influence the development of major components of emotional intelligence. Two temperamental qualities were specified to be significant determinants of emotional regulation: emotional intensity which involves latency, threshold, and rise time of emotions; and attentional process.

The basic principle of the investment model of EI then is that an individual possesses a range of emotional responses from temperament through rule-based competencies, to more advanced emotional competencies as intelligence. This model proposes that the varied repertoire of emotionally intelligent behaviors is learned over time and involves biological, informational, and metacognitive aspects of emotion, dependent on temperament, socialization and selfregulatory processes respectively.

Rule-based learning. The second level of the investment EI development model includes rule-based learning which involves caregiver socialization procedures that influence the child's social knowledge, attitudes and skills and aids in the strengthening of a child's emotional competence. Lewis and Saarni (as cited in Zeidner et al.,
2009, p. 149) suggest that caregiver influences may also be indirect as in the form of observation and modeling of emotional behavior and competencies.

In the same vein, Izard (2001) suggests that EI is based on learned adaptive skills influenced by temperament, and is discrete from the biological level. That is, it is possible for EI to be not only a representation of a general, inherent temperament but is a set of specific ability for learning emotion-regulation skills. For example, Zeidner et al. (2009) suggests that the ability to label emotions involve interpretative processes dependent on cognitive development; that the learning of display and coping rules depend on language development, concluding that conventional intelligence may affect the development of emotional competencies.

Zeidner et al. (2009) proposed that the basic, rulebound skills are influenced by socialization processes and by the family environment.

Child-adult attachment. The investment model posits that the quality of the caregiver-child attachment is a major requirement for developing emotional competencies. This relationship provides a basis for the child's creating a positive working model of both self and personal relationships. That is, the experiences with the caregiver serve as the foundation for sense of security, self-esteem and emotional competencies.

Emotional climate of family and caregiver expressiveness. Zeidner et al. (2009) suggest that the family is the "primary context in which children learn various facets of emotions" (p. 150). The model posits that emotional climate in the home is due largely to two factors: the manner in which the caregiver expresses positive and negative emotions; and the caregiver's response to the child's emotional expressiveness. Thus, familial socialization of emotional competencies is carried out, to a large extent, by the caregiver's attitude toward a child's emotional expressiveness and his or her ability to manage child's emotions.

Reinforcement of emotionally competent behaviors. Social learning theories suggest children's emotional behaviours and skills are contingent upon reinforcements and punishments. By rewarding certain behaviors, intentionally or inadvertently, parents reinforce certain emotional expressions while extinguishing others. A certain set of parenting techniques, referred to as "rewarding socialization of emotion," contributes to social competencies of children (Denham, 1998, as cited in Zeidner et al., 2009). In fact, parental support and encouragement were found to predict of children's ability to regulate their emotions (Grolnick \& Ryan, 1989).

By contrast, another set of parental behaviors, labelled as "punitive socialization," negatively affects children's social abilities. Parents' punitive responses are shown to be positively linked to increased incidence of negative emotions (Eisenberg, Fabes, Murphy, Shepard, 
Guthrie, Mazsk, Poulin, \& Jones, 1999). Zeidner et al. (2009) then proposed that parental child-rearing styles and practices relate to the development of children's emotional competencies.

Socialization and child-rearing practices. Zeidner et al. (2009) propose that parental warmth is linked to the development of emotional competence in children. The model predicts that when parents are responsive and warm, children are better at social adjustment. When parents are skilled at regulating their own emotions, children also learn emotional skills that are protective against the stress and overwhelming demands.

Positive and negative affect. This EI development model further suggests that a positive affect, such as happiness, signals an enduring pattern of emotional wellbeing. Positive affect appears to be critical in the beginnings of social interaction and sharing of positive feelings. Negative affect, such as sadness or anger, when inappropriately displayed, has been shown to be detrimental to the development of emotional competence.

Socialization of emotions through behavioral techniques. Mayer and Salovey (2000) suggest that children learn from role models how to process and manage emotional information and experiences. The model predicts that individuals high in EI have learned from ideal role models how to process and regulate emotional information to maintain workable relationship with others. It is assumed that a child whose care-giver shows high EI-related behaviours in regular interactions is likely to imitate these behaviours such that they become part of his or her behaviour repertoire.

Strategic self-regulatory behavior. The development of strategic self-regulatory behavior is the third level in the investment model of EI. This level is related to the development of intelligent self-regulation of emotion. The investment model assumes that by self-regulating techniques, children will learn to initiate and maintain real emotional states, which may be positive or negative. Children also learn to communicate their emotions in ways that allow them to meet emotion-regulation goals, such as maintaining social interaction. The model identifies emotions that need to be regulated: those which are aversive, those which are overpowering, and those emotions that need to be enhanced, such as happiness.

Socialization of self-regulatory behavior. The investment model predicts that parental instruction and communication on emotion is the most direct aspect of emotion socialization contributing to the development of strategic emotion regulation. Parental coaching consists of verbally explaining a difficult situation; directing the child's attention to significant emotional cues; showing the relationship between an observed event and its emotional consequences; helping the child understand and manage her or his behavior; and dividing social interactions into manageable components.
The basic principle of the investment model of EI then is that an individual possesses a range of emotional responses from temperament through rule-based competencies, to more advanced emotional competencies as intelligence. This model proposes that the varied repertoire of emotionally intelligent behaviors is learned over time and involves biological, informational, and meta-cognitive aspects of emotion, dependent on temperament, socialization and selfregulatory processes respectively.

In sum, the multilevel investment model describes the distinct levels of emotional functioning influenced by biological and socialization processes.

\section{TEMPERAMENT AND EMOTIONAL INTELLIGENCE}

Temperament is defined as 'individuals' differences in reactivity and self-regulation assumed to have a constitutional basis" (Rothbart, 1981, p.40). The term "constitutional" in this definition, is understood to refer to the biological structure of an individual that is considered relatively permanent, and is influenced over time by heredity, maturation and experience.

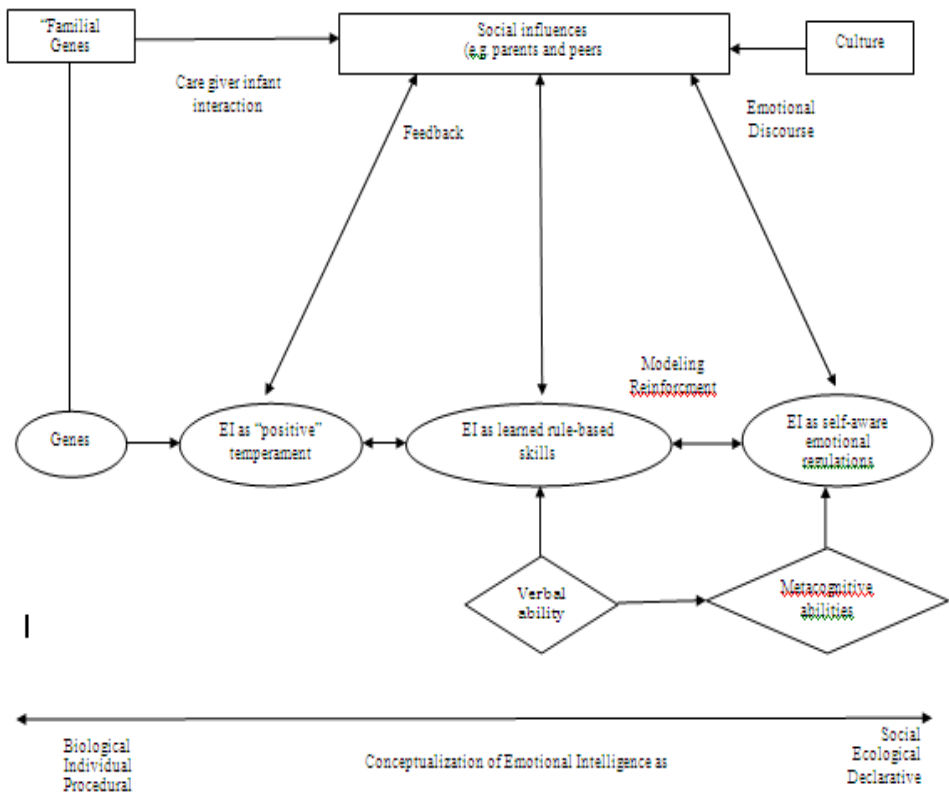

Figure 2. Investment model of emotional development

The term "reactivity," relates to qualities of excitability, responsivity, and arousability with which an individual responds to events in the environment. The term "selfregulation" encompasses the neural and behavioral process that moderates reactivity, which in turn, include attentional and behavioral processes of approach-avoidance.

The following presents literature which shows that temperament is linked to emotional intelligence, as well as the evidence that emotional intelligence can be measured reliably separate from measures of temperament. 
Current thinking holds that biological and constitutional factors contribute to emotional intelligence development (Zeidner et al., 2009). Temperamental characteristics are thought to be related to particular brain systems that control emotion, motivation, and attention.

The current study assumes that temperament is related to brain systems. This study argues that emotional competencies are influenced mostly by environmental forces that interact with an individual's biological constitution.

Infants have been observed to perceive, distinguish, and respond to emotional signals (Izard, 2001). This suggests that there are emotional competencies that are independent of learning or experience. Eisenberg, Fabes and Losoya (1997) found that infants differ in temperamental factors such as emotional intensity. Kagan, Reznick, and Snidman (1987) also found difference in expression of inhibition among infants, while Rothbart (1989) found infants to differ in emotionality. It is highly likely that these factors influence perception, expression of basic emotions, and primitive strategies to control emotion.

Zeidner et al. (2009) suggest that temperament influences not only the intensity of emotional experience but also strategies for emotional regulation. For example, individuals with distress-prone temperament are likely to be resistant, angry, argumentative, and clingy which Kochanska and Coy (2002) described as a dysregulative style.

However, Zeidner et al. (2009) added that temperament, along with environmental forces, can hinder or help EI development through several processes. First, individuals who are in harsh environments may express more negative emotions, and secondly, children predisposed to experience negative affect may be more prone to emotional ill-health.

Lochman and Lenhart (1993) reported that problems that may arise from unpleasant environmental conditions and temperament include difficulty in emotion regulation, in forming connections between strong emotions, and the language that can articulate them. Emotional intelligence resides, in part, on learned adaptive skills influenced by temperament. Therefore, it reflects temperamental qualities as well as specific emotion-regulation skills.

Moreover, reviews of EI self-report measures have repeatedly shown that EI relates to two broad components of temperament: negative affectivity and positive affectivity. Negative affectivity, also referred to as neuroticism or NA, is described as trait sensitivity to negative events. Individuals with high scores in negative affectivity experience a wide range of negative moods such as anxiety, sadness, guilt, hostility and self-dissatisfaction, and tend to have low trait self-esteem. On the other hand, "positive affectivity", or extroversion, is defined as trait sensitivity to positive situations. High scorers tend to feel happy, excited, energetic, sociable, bold, self-assured, proud, and confident. Low scorers in extraversion tend to feel bored, flat, disinterested, and indifferent (Ciarrochi, Forgas \& Mayer, 2001).

Ciarrochi, Forgas, and Mayer (2001) offered three possible explanations for the relationship between temperament and emotional intelligence: First, individuals who experience a wide range of negative emotions will require more skill to control these emotions. For example, an individual who finds difficulty in controlling anger is most likely to have an "angry" temperament and may lack skill to control his temperament. Second, people high in negative affectivity tend to have less stable affective experiences. These fluctuations of moods make it difficult for them to understand the nature and source of their emotions. Thirdly, individuals with good temperament, that is, low NA (negative affectivity) and high PA (high affectivity), tend to be confident about their abilities in general.

Concerns have been raised on the overlapping effects of EI and temperament on psychological functioning. In fact, Ciarrochi et al. (2001) found from self-report EI measures that there is a strong overlap between EI and temperament: For example, people with high EI tend to have good mental health. With that as a given, it can then be said that that EI leads to improved mental health. However, it is just as logical to argue that people with high EI have good temperament, (i.e. low NA and high PA), and it is good temperament that predicts superior mental health.

Zeidner, Matthews, Roberts, and MacCann (2003) suggest that temperament influences an individual's emotional state as well as his or her strategies for emotional regulation. For example, Kochanska and Coy (2002) found that individuals with distress-prone temperament, those whose negative affectivity is high, may engage in "dysregulative" style of emotional regulation such as being offensive, opposing and angry when placed in threatening settings.

Additionally, two temperament dimensions namely, fearfulness and effortful control, were found to be predictors of children's compliance to their mother's requests, where compliance is considered as a form of self-regulation as the child must adjust his or her behavior to parental demands. Zeidner et al. (2003) then propose that it is possible that emotional intelligence reside in a profile of temperaments: "low negative affectivity, moderate extraversion, and high effortful control" (p. 79).

It is also necessary to distinguish the effects of EI and temperament. This has been addressed by two methods: The first is by a number of performance measures that were designed to minimize the EI and temperament overlap. The second method involved examining the effect of EI on psychological functioning while statistically controlling for temperament. This second method has been used with some measure of success: emotional clarity successfully predicted ruminative thinking after controlling for aspects of temperament. 
Adolescents with high EI were found to have better social support, better at recognizing facial expressions, and at engaging in behavior that maintains positive moods, after controlling for the effects of NA and PA (Ciarrochi et al., 2001).

This study demonstrated that self-reported EI has predictive power separate from that of temperament. It can then be said that EI can be measured reliably, is distinct from measures of temperament, and can predict important behaviors.

Temperament is defined as “individuals' differences in reactivity and self-regulation assumed to have a constitutional basis" (Rothbart, 1981, p.40). This study hypothesizes that temperament is linked to emotional intelligence.

This study seeks to answer this question.: Does temperament predict the level of emotional intelligence among adolescents

\section{DESIGN}

\section{Design and Sample}

As a predictive research, this study aimed to examine whether temperament predicts emotional intelligence. There are 300 respondents in this study, $166(55 \%)$ were females and 134 $(45 \%)$ were males. The average age of respondents was 19.10 years $(S D=1.956)$.

\section{Data Collection}

Communication was sent to the college deans and teachers of the three schools, requesting approval to conduct a research survey. When request was approved, respondents were gathered in large groups. Respondents were informed about the nature of the study and their participation and were then tested. Respondents were assured of confidentiality of their results, and were informed that their individual results will be made available for them. They were also informed to raise questions they find unclear. Participants completed seven questionnaires in about an hour and 20 minutes. The surveys submitted were reviewed for completion by the researcher when the survey was conducted. Completed survey sheets were inspected to check for missing information. Data gathered were then screened, encoded, analyzed, and interpreted.

\section{Data Analysis}

Descriptive statistics were used to establish the profile of research respondents, the range of scores, means, and standard deviations for all measured items. Regression analysis was performed to test whether perceived parenting style significantly predict level of emotional intelligence among adolescents.

Research Instrument
Trait Meta-Mood Scale (TMMS). Emotional intelligence is defined from the standpoint of the Mayer and Salovey EI model: as the ability to "perceive emotions, to access and generate emotions so as to assist thought, to understand emotions and emotional meanings, and to reflectively regulate emotions to promote both better emotion and thought" (Mayer \& Salovey,1997, p. 5). The trait metamood scale was the first assessment measure developed by the authors who first identified the EI construct. The TMMS was designed to measure individual differences in the processes of emotional regulation, which includes emotional awareness that further involves monitoring, evaluation, and management of feelings (Mayer, Salovey, Goldman, Turvey, Palfai, 1995) (Appendix B). The TMMS is based on the early notions of EI put forth by Mayer and Salovey (1990).

The TMMS assessed the extent to which individuals attend to their feelings, the clarity of their experience of these feelings, and their ability to regulate their feelings. The TMMS is found to be useful in identifying core individual differences that describe emotionally intelligent individuals. Early EI studies by Mayer and Gaschke (1988) showed that individuals regularly reflect, monitor, evaluate, and manage their feelings; they termed this process as meta-mood experience. The TMMS is designed to assess "relatively stable individual differences in people's tendency to attend to their moods and emotions, discriminate clearly among them, and regulate them (Salovey, Mayer, Goldman, Turvey, \& Palfai, 1995, p.128). It is designed to measure three EI constructs, namely, attention to emotion, clarity of emotion, and emotion repair. Attention to emotion conveys the extent to which individuals notice and think about their feelings; clarity of emotions refers to the ability to understand one's moods; and emotion repair pertains to the degree to which individuals regulate their moods.

The TMMS is found to be an adequate operationalization of the aspects of emotional intelligence (Salovey et. al, 1995). This measure is able to assess individual differences in people's ability to understand, express, and regulate their feelings as well as their ability of using their feelings adaptively. The scales in the TMMS, namely, attention to feelings, clarity of feelings, and ability to regulate one's emotions are fundamental to emotional intelligence (Salovey, et al., 1995).

Previously reported internal consistencies for each subscale are high attention to emotion, $\alpha=.86$; emotional clarity, $\alpha=.87$; and emotion repair $\alpha=.82$ (Salovey, et al., 1995). Validation studies have demonstrated that these constructs can be sufficiently differentiated from related constructs such as neuroticism and repression. The use of self-report measures to assess emotional intelligence "provides a straightforward and economical means for measuring individual differences in emotional functioning." (Zeider et al., 2009,p. 27).Salovey, et al. (1995) did not specify a clear-cut scoring range for interpreting scores. Total EI scores of the adapted TMMS ranged from low of 25 
to high of 125 . Using prorate calculation, scores in the range of 30 to 70, suggest a need to work on emotions, scores near 71 to 110 , suggest a good enough handle on emotions; and 111 to 150 , suggest excellent emotional skills. For emotional attention subscale: scores near 13 to 31 suggest a need to work on emotional awareness; 32 to 48 , suggest growing emotional awareness; and 49 to 65 is considered excellent emotional attention. For subscale emotional clarity: scores near 11 to 25 suggest some confusion; scores near 26 to 40, suggest growing clarity; and scores near 41 to 55 is excellent emotional clarity. For emotional repair: scores 6 to 14, suggest a need to improve self-regulation; near 15 to 22; suggest attempts at emotional repair; and scores near 23 to 30 suggest excellent emotional repair.

Adult Temperament Questionnaire (ATQ). In this study, temperament was defined as 'individuals' differences in reactivity and self-regulation assumed to have a constitutional basis" (Rothbart, 1981, p.40). Temperament was assessed in this study using the Adult Temperament Questionnaire (ATQ) was adapted from the Physiological Reactions Questionnaire developed by Derryberry and Rothbart (1988) as shown in Appendix C. The ATQ is a selfreport measure designed to assess four dimensions: negative effect, effortful control, extraversion or surgency, and orienting sensitivity.

Each temperament dimension measures some subscales: negative affect assesses fear, sadness, discomfort and frustration; effortful control measures attentional, inhibitory, and activation control; extraversion evaluates sociability, positive affect, and intensity of pleasure; and orienting sensitivity assesses neutral perceptual sensitivity, affective sensitivity, and associative sensitivity. This test measure is appropriate for use for individuals above 15 years old (Evans \& Rothbart, 2007).

This study used the 77-item short-version of the ATQ. To score the ATQ, reversed items, those marked with "R" need to be reverse-coded. To score the main scales, all Likert-responses are summed up within a given scale together and divide by the number of the valid item responses. To score factor scales, the Likert scores were also added for all of the items of scales for every given factor scale and divided by the number of items of that factor scale.

The initial reliability testing in this study showed ATQ, with reliability coefficient of .562 , to be low. This is not unexpected as the ATQ is a multidimensional measure, assessing four temperament constructs: negative affect, effortful control, extraversion, and orienting sensitivity. The initial reliability testing also revealed low reliability scores for all subscales: negative affect (26 items; $\alpha=.60$ ), effortful control (19 items; $\alpha=.49$ ); extraversion (17 items; $\alpha=.46$ ), and orienting sensitivity (15 items; $\alpha=.58)$.

As recommended by Field (2013), items which were indicated to reduce the reliability were removed from the subscale-measures. The reliability scores increased for all four of the temperament subscale measures: negative affect (21 items; $\alpha=.73$ ), effortful control (10 items; $\alpha=.64)$, extraversion (10 items; $\alpha=.60)$, and orienting sensitivity (11 items; $\alpha=.73)$. The modified temperament measure which now contains 52 items was used in the analyses. This modified measure is named here as Adult Temperament Questionnaire-Adapted (ATQ-A), presented in Appendix C1.

There are no published norms in determining high, middle, or low scores in the ATQ. Evans and Rothbart (2007) recommended the use of local norms, that is, the mean and standard deviation derived from the local sample, to relate the individual scores. The means and standard deviations of the sample were used as local norms in computing for group scores. For negative affect scale, scores below 2.6 are considered low, scores 3 to 5 are average, and scores 6 and above are high, reflecting fear, sadness, discomfort and frustration.

For effortful control scale, scores around 3 are low, scores around 3.5 to 5, are average, whereas scores 6 and over are considered high, reflecting ability to focus and shift attention at will. For extraversion scale, scores below 2 are considered low, scores about 3.5 to 5 are average, and scores over 6 are high, reflecting sociability and positive feelings in social situations. For orienting sensitivity subscale, scores below 3 are low, scores about 4 to 5.5 are average, and scores over 6 are considered high reflecting sensitivity to low valenced stimuli.

\section{RESULTS}

This section presents the findings of the study: description of the variables of interest, namely, temperament, and emotional intelligence,

Description of Emotional Intelligence, and Temperament Scores

Descriptive statistics were used to establish the profile of research respondents, the range of scores, means, and standard deviations for all measured items. Measures of central tendency were computed to summarize the variables of interest in this study. Table 1 shows the means and standard deviations of scores of emotional intelligence, and temperament.

Emotional intelligence. As shown in Table 1, the respondents obtained mean score of 87.52 ( $S D=9.08$ ) considered in the average range and suggesting an adequate awareness of emotions, clarity, and self-regulation. For EI subscale emotional attention, respondents reported average score $44.15(S D=5.98)$, suggesting a growing emotional awareness. For clarity of feelings, respondents obtained mean score of $24.90(S D=3.97)$ considered as average scores, suggesting growing emotional clarity. For emotional repair, respondents obtained mean score of $15.50(S D=2.64)$ in emotional repair, suggesting adequate ability at mood management. 
Temperament. Table 1 also shows the mean and standard deviation scores of four subscales of temperament. Respondents obtained a mean score of $4.11(S D=.70)$ for negative affect, suggesting moderate levels of fear, sadness, discomfort, or frustration. The obtained score for effortful control was $4.44(S D=.78)$ suggesting moderate ability to voluntarily shift and focus attention, and inhibit or initiate actions. The respondents obtained a mean score of 4.36 $(S D=.82)$ for extraversion, suggesting average sociability and positive affect. The mean score for orienting sensitivity was 4.63

$(S D=.84)$, suggesting adequate sensitivity to internal or external stimuli

\section{Temperament and Emotional Intelligence}

Multiple regression analysis was used to test whether temperament, in terms of its subscales, namely, negative affect, extraversion, effortful control, and orienting sensitivity, significantly predict the level of emotional intelligence of college respondents. The results of the regression indicated temperament explained $7 \%$ of the variance $\left(R^{2}=.068\right.$, $F(4,295)=5.339, p<.001)$. Effortful control $(\beta=.184, p<$ $.01)$ was found to significantly predict overall EI. Statistical power, computed post-hoc was about adequate at .74.

Table 1: Means and Standard Deviation Scores of Emotional Intelligence, and Temperament

\begin{tabular}{|c|c|c|c|c|}
\hline Variable & Subscales & $M$ & $S D$ & Range \\
\hline $\begin{array}{c}\text { Emotional } \\
\text { Intelligence }\end{array}$ & & 87.52 & 9.08 & $25-125$ \\
\hline & $\begin{array}{c}\text { Attention to } \\
\text { Emotions }\end{array}$ & 44.15 & 5.98 & $13-65$ \\
\hline & Clarity of Emotions & 24.90 & 3.97 & $8-40$ \\
\hline & Repair of Emotions & 15.50 & 2.64 & $12-20$ \\
\hline Temperament & Negative Affect & 4.11 & .70 & $1-7$ \\
\hline & Effortful Control & 4.44 & .78 & $1-7$ \\
\hline & Extraversion & 4.36 & .82 & $1-7$ \\
\hline & Orienting Sensitivity & 4.63 & .84 & $1-7$ \\
\hline
\end{tabular}

\section{DISCUSSION}

The central research question in this study is to examine whether temperament is is significant

The limitations of the current work, specific recommendations for future research, implications and general recommendations are also presented.

A total of 300 respondents were assessed in their levels of emotional intelligence, the perceived parenting styles of their primary caregivers, their temperament, and the state of their mental health, in terms of perceived self-efficacy, resilience, anxiety, and depression.
In terms of their levels of emotional intelligence, respondents' scores reflect moderate, growing emotional skills as emotional attention, clarity and repair. This is understandable in that, at the stage of late adolescence, adolescents develop complex emotional understanding. They are at a developmental stage where they are able to understand social situations, and how these can potentially generate emotional reactions. They are also able to understand emotional display rules and scripts, and hence are able to manage displays of emotion (Saarni, 1999). With more advanced cognitive skills, they are able to understand someone else's perspective, other than their own (Eccles, 1999).

In terms of temperament, respondents' score reflect moderate in negative affect as fear, sadness, discomfort, or frustration; moderate in effortful control as voluntary regulation of actions and attention; moderate in extraversion that involves sociability and positive affect; and moderate in orienting sensitivity to internal stimuli such as thoughts, images, or moods, and environmental prompts.

\section{Temperament and Emotional Intelligence}

Temperament is referred to here as the relatively stable emotions and behavioral predispositions influenced by heredity, and was considered here as having four sub dimensions, namely negative affect, extraversion, effortful control, and orienting sensitivity.

The results of this study supported the hypothesis that temperament is a significant predictor of emotional intelligence.

Zeidner et al.'s (2009) multilevel investment model of emotional intelligence development identified temperament and biology as the foundational first level of EI development.

Temperament is said to provide the foundational structure for the learning and acquiring of emotional skills. They assumed that temperament, as in other personality traits, have genetic components, and are therefore, heritable. Citing several other studies, Zeidner et al. (2009) mentioned heritability estimates of EI-related temperament traits: For example, inhibition with possible link to emotional regulation is found to be heritable (Plomin \& Stocker, 1989, as cited in Zeidner, et al. 2000); and empathy, too is found heritable (Davis, Luce, \& Kraus, 1994, as cited in Zeidner, et al. 2000).

That the learning of EI is based on temperament is supported by research. Izard, Trentacosta, King, Morgan, and Diaz (2007) concluded that EI is a learned adaptive skill, the aptitude for which is affected by temperament, and that EI reflects both temperamental characteristics as well as aptitudes to learning EI skills.

It is then plausible to say that temperament directly relates to EI as a set of biologically-based qualities, and indirectly, through readiness to learn emotional competencies. This is supported by the multilevel investment model of EI 
development (Zeidner et al., 2009) in which the first level, the biological-based temperamental qualities, is set as a foundation for the subsequent second-level, that is, the learning of emotional skills from parents and significant caregivers.

Specifically, the results showed the temperament component, effortful control, to positively predict emotional intelligence. Derryberry and Rothbart 1988) described effortful control is as relatively deliberate control functions important for goal-directed behaviors. Its subcomponents includes attentional control, which pertains to the capacity to focus and shift attention at will; inhibitory control, which relates to the ability to suppress inappropriate approach behavior; and activation control which involves the capacity to perform a behavior despite a strong tendency to avoid it (Derryberry \& Rothbart, 1988). The results of this study, then, suggest that effortful control can be an important quality for emotional attention and emotional self-regulation.

Effortful control, as a regulatory aspect of temperament, is responsible for suppressing behaviors that are deemed inappropriate for the situation at hand. It also serves to override potential emotional responses. It allows one to initiate alternate responses and maintain appropriate behaviors. It allows one to voluntarily move one's focus from one point to another.

With these as a given, that effortful control involves activation and inhibitory control as well as focused attention, it is logical to imagine that, effortful control is related to emotional intelligence, as is found in this study .

The result of this study is consistent with previous research. Eisenberg and Fabes (1995) identified the temperamental attribute, effortful control, as a determinant of emotional regulation. The control processes of temperament, which involve the ability to focus and shift attention, and initiating and suppressing behaviors at will, was found to be related to emotional regulation.

Cutting edge research on temperament revealed relationship between effortful control and executive attention, the ability to manage attention toward set goals. Imaging studies found effortful control to be linked areas of the brain that involved in self-regulation (Posner, 2003).

In sum, it can be said that temperament plays an important role in the development of EI, and that effortful control appears to be the temperamental quality that underlies emotional intelligence skills, such as emotional attention and self-regulation.

This is relevant in that it informs parents, teachers, counselors, and clinicians, that because EI is temperamentbased, there is a critical window of time during which emotional intelligence skills should be taught and learned.

Overall, gender had not been shown to predict adolescent EI or any of the components of mental health.
Authoritative parenting style had been revealed to be important to the development of EI among adolescents. Parenting styles had been found to have a direct influence and an indirect influence on adolescent mental health through EI. Lastly, temperament was found to predict EI: Effortful control, temperament component, was found to specifically predict EI. Temperament was revealed to have a direct and indirect influence on adolescent mental health through EI.

\section{LIMITATIONS AND RECOMMENDATIONS FOR FUTURE RESEARCH}

The limitations of this current work are presented here as well as some recommendations to address this work's limitations in future research of the same theme.

\section{Measurement}

The first limitation is concerned with this study's reliance on self-report measures which focus on the individual's stated self-beliefs, which may not encompass the entire range of emotional competencies, psychological distress or psychological health. With the use of self-report measures there exists a likelihood of the disparity between respondent perception and actual emotional competencies and experiences. However, the variables of interest of this study are subjective experiences which lend to the difficulty in measuring them objectively. They are considered, too, as perception-based and thus are best assessed by the respondents themselves.

Additionally, the use of self-report measure of EI has been shown to be useful as people, in general, act in consonance with their expressed beliefs of their emotional intelligence (Bandura, 1997). Self-report approach them may still be considered a useful tool to collect data and make predictions based on self-reported data (Petrides \& Furnham, 2003). Nonetheless, future studies should include the use of ability measures of EI, as in the Mayer-Salovey-Caruso Emotional Intelligence Test and this assesses emotional competencies. Currently, this is the sole ability-based measure of EI, and because of its cost, is not easily accessible for student-researchers.

The measure for temperament, Adult Temperament Questionnaire (ATQ) was found to have low reliability coefficients at first testing. When systematically modified, and at second testing, it has shown itself to be reliable. There may then be a need to develop and validate measures, such as measures of EI and temperament, relevant to the Filipino culture. These new measurements would improve the reliability and validity of research results and would be a step forward in Sikolohiyang Pilipino in the understanding of the Filipino emotionality.

\section{Generalizability}

The second limitation relates to the study population which is limited to college students of local universities in Cagayan de Oro, with their assent. This cross section of the 
population is of special interest to me as a researcher in wanting to systematically understand mental health of our students and to help them address their psycho emotional issues. This sampling limitation may influence the generalizability of the research outcome to other sections of the general population.

In sum, this study's limitations point to several, promising avenues of EI research that may be a step forward in the description, explanation, prediction, and application of the EI construct.

\section{THEORETICAL IMPLICATIONS AND RECOMMENDATIONS}

This study's result is has theoretical relevance. The findings revealed the impact of temperament on EI conformed to the multilevel investment model proposed by Zeidner et al. (2006). The results, then, provided empirical support to the hypothesized relationships between temperament and emotional intelligence. These results provided description and explanation of EI development.

This study explored the relationships between temperament and emotional intelligence. Based on the obtained results, it is recommended that future research be conducted to examine in "causal" relationships among temperament, emotional intelligence, and mental health through path analysis

This study was conducted to examine the role of temperament on emotional intelligence. This study of EI among Filipino adolescents begins an important process of understanding the development of EI in non-adult age groups. This study has demonstrated that temperament play essential roles to the development of emotional intelligence. These are significant for Filipino psychological research and are relevant in the understanding and enhancing the Filipino adolescents' mental and psychoemotional health.

\section{REFERENCES}

[1] Abdollahi, A., \& Abu Talib, M. (2015). Emotional intelligence moderates perfectionism and test anxiety among Iranian students. School Psychology International, 36(5), 498-512.

[2] Abdon, L., Farin, E. N., \& Farin, A. N. (2017). Emotional intelligence, leadership qualities and decision-making practices of female administrators in selected secondary schools in Region III, Philippines. Asian Journal of Management Sciences and Education, 6(1), 28-36.

[3] Asidao, Z. (2001). Emotional intelligence: Its influence on the job performance of managers of selected educational institutions in the division of City Schools, Manila. Unpublished doctoral dissertation, Technological University of the Philippines, Manila.

[4] Augusto-Landa, J., \& Montes-Berges, B. (2009). Perceived emotional intelligence, health and somatic symptomatology in nursing students. Individual Differences Research, 7(3), 197-211. Retrieved from PsycINFO database.

[5] Boyd, C. P., Gullone, E., Kostanski, M., Ollendick, T. H., \& Shek, D. T. (2000). Prevalence of anxiety and depression in Australian adolescents: Comparisons with worldwide data. The Journal of Genetic Psychology, 161(4), 479-492

[6] Cha, C., \& Nock, M. (2009). Emotional intelligence is a protective factor for suicidal behavior. Journal of the American Academy of
Child \& Adolescent Psychiatry, 48(4), 422-430. doi:10.1097/CHI.0b013e3181984f44.

[7] Chan, D. (2004, June). Perceived emotional intelligence and selfefficacy among Chinese secondary school teachers in Hong Kong. Personality \& Individual Differences, 36(8), 1781. doi:10.1016/j.paid.2003.07.007.

[8] Ciarrochi, J., Dean, F., \& Anderson, S. (2002). Emotional intelligence moderates the relationship between stress and mental health. Personality and Individual Differences, 32(2), 197-209. doi: 10.1016/S0191-8869(01)00012-5.

[9] Ciarrochi, J., Forgas, J., \& Mayer, J. (2001). Emotional intelligence in everyday life: A scientific inquiry. New York, NY US: Psychology Press. Retrieved from PsycINFO database.

[10] Ciarrochi, J., Deane, F., \& Anderson, S. (2002). Emotional intelligence moderates the relationship between stress and mental health. Personality and Individual Differences 32(1).197-20. doi: 10.1016/S0191-8869(01)00012-

[11] Ciarrochi, J., Hynes, K., \& Crittenden, N. (2005). Can men do better if they try harder: Sex and motivational effects on emotional awareness. Cognition and Emotion, 19(1), 133-141. doi: 10.1080/02699930441000102.

[12] Ciarrochi, J., Chan, A., \& Bajgar, J. (2001). Measuring emotional intelligence in adolescents. Personality and Individual Differences, 31(7), 1105-1119. doi:10.1016/S01918869(00)00207-5.

[13] Ciarrochi, J. V., Chan, A. C., \& Caputi, P. (2000). A critical evaluation of the emotional intelligence construct. Personality and Individual Differences, 28(3), 539-561. doi:10.1016/S01918869(99)00119-1

[14] Davis, S. K., \& Humphrey, N. (2012). The influence of emotional intelligence (EI) on coping and mental health in adolescence: Divergent roles for trait and ability EI. Journal of adolescence, 35(5), 1369-1379.

[15] Derryberry, D., \& Rothbart, M. (1988). Arousal, affect, and attention as components of temperament.Journal of Personality and Social Psychology, 55(6), 958-966. doi:10.1037/00223514.55.6.958.

[16] Dinglasan, Q. (2004). Correlation of emotional intelligence to the academic performance of Notre Dame University Elementary Training Department pupils. Unpublished master's thesis, Notre Dame University, Cotabato City.

[17] Eccles, J. S. (1999). The development of children ages 6 to 14. The future of children, 30-44.

[18] Eisenberg, N., Fabes, R., Murphy, B., Shepard, S., Guthrie, I., Mazsk, P., et al. (1999). Prediction of elementary school children's socially appropriate and problem behavior from anger reactions at age 4-6 years. Journal of Applied Developmental Psychology, 20(1), 119-142. doi:10.1016/S0193-3973(99)800070.

[19] Eisenberg, N., Fabes, R., Schaller, M., \& Carlo, G. (1991). The relations of parental characteristics and practices to children's vicarious emotional responding. Child Development, 62(6), 13931408. doi:10.2307/1130814.

[20] Eisenberg, N., \& Fabes, R. A. (1995). The relation of young children's vicarious emotional responding to social competence, regulation, and emotionality. Cognition and Emotion, 9(2-3), 203228. doi:10.1080/02699939508409009

[21] Eisenberg, N., \& Fabes, R. A. (1995). The relation of young children's vicarious emotional responding to social competence, regulation, and emotionality. Cognition and Emotion, 9(2-3), 203228. doi:10.1080/02699939508409009

[22] Eisenberg, N., \& Morris, A. (2002). Children's emotion-related regulation. In R. V. Kail, R. V. Kail (Eds.), Advances in child development and behavior, Vol. 30 (pp. 189-229). San Diego, CA US: Academic Press. Retrieved from EBSCOhost.

[23] Eisenberg, N., Fabes, R. A., Guthrie, I. K., \& Reiser, M. (2000). Dispositional emotionality and regulation: Their role in predicting quality of social functioning. Journal of Personality and Social Psychology, 78(1), 136-157. doi:10.1037/0022-3514.78.1.136. 
[24] Evans, D. E., \& Rothbart, M. K. (2008). Temperamental sensitivity: Two constructs or one? Personality and Individual Differences, 44(1), 108-118. doi:10.1016/j.paid.2007.07.016

[25] Evans, D., \& Rothbart, M. (2009). A two-factor model of temperament. Personality and Individual Differences, 47(6), 565570. doi:10.1016/j.paid.2009.05.010.

[26] Evans, D., \& Rothbart, M. (2007). Developing a model for adult temperament. Journal of Research in Personality, 41(4), 868-888. doi:10.1016/j.jrp.2006.11.002.

[27] Evans, D., \& Andrews, L. (2005). If your adolescent has depression or bipolar disorder: An essential resource for parents. New York, NY US: Oxford University Press. Retrieved from PsycINFO database.

[28] Evans, D. E., \& Rothbart, M. K. (2007). Development of a model for adult temperament. Journal of Research in Personality, 41, 868-888.

[29] Evans, D. E., \& Rothbart, M. K. (2007). Developing a model for adult temperament. Journal of Research in Personality, 41(4), 868-888. doi:10.1016/j.jrp.2006.11.002

[30] Field, A. (2013). Discovering statistics using IBM SPSS statistics. sage.

[31] Galla, V. (2006). Emotional intelligence: Its relationship with managerial skills. Unpublished Doctoral dissertation. University of Cordilleras, Baguio City, Phillipines.

[32] Grolnick, W., \& Ryan, R. (1989). Parent styles associated with children's self-regulation and competence in school. Journal of Educational Psychology, 81(2), 143-154. doi:10.1037/00220663.81.2.143.

[33] Izard, C. (2001). Emotional intelligence or adaptive emotions?. Emotion, 1(3), 249-257. doi:10.1037/15283542.1.3.249.

[34] Izard, C., Trentacosta, C., King, K., Morgan, J., \& Diaz, M. (2007). Emotions, emotionality, and intelligence in the development of adaptive behavior. In G. Matthews, M. Zeidner, R. D. Roberts, G. Matthews, M. Zeidner, R. D. Roberts (Eds.), The science of emotional intelligence: Knowns and unknowns (pp. 127-150). New York, NY US: Oxford University Press. Retrieved from EBSCOhost.

[35] Jones, S., Eisenberg, N., Fabes, R., \& MacKinnon, D. (2002). Parents' reactions to elementary school children's negative emotions: Relations to social and emotional functioning at school. Merrill-Palmer Quarterly: Journal of Developmental Psychology, 48(2), 133-159. doi:10.1353/mpq.2002.0007

[36] Kagan, J., Reznick, J., \& Snidman, N. (1988). The physiology and psychology of behavioral inhibition in children. Annual Progress in Child Psychiatry \& Child Development, 102-127. Retrieved from PsycINFO database.

[37] Kong, F., Zhao, J., \& You, X. (2012). Emotional intelligence and life satisfaction in Chinese university students: The mediating role of self-esteem and social support. Personality and individual differences, 53(8), 1039-1043.

[38] Leano, B. (2006). Emotional intelligence and job satisfaction of faculty in two selected nautical schools. Unpublished master's thesis). Technological University of the Philippines, Manila.

[39] Lochman, J., \& Lenhart, L. (1993). Anger coping intervention for aggressive children: Conceptual models and outcome effects. Clinical Psychology Review, 13(8), 785-805. doi:10.1016/S02727358(05)80006-6.

[40] Manzano, A. (2004). Relationship between emotional intelligence and academic performance. Unpublished master's thesis. University of San Carlos, Cebu City, Phillippines.

[41] Mayer, J. (2004). What Are the Advantages of a More Focused Approach to EI? Retrieved from http://www.unh.edu/emotional_intelligence.

[42] Mayer, J. D., \& Gaschke, Y. N. (1988). The experience and metaexperience of mood. Journal of Personality and Social Psychology, 55(1), 102-111. doi:10.1037/0022-3514.55.1.102

[43] Mayer, J., \& Geher, G. (1996). Emotional intelligence and the identification of emotion. Intelligence, 22(2), 89-114. doi:10.1016/S0160-2896(96)90011-2.
[44] Mayer, J., \& Salovey, P. (1995). Emotional intelligence and the construction and regulation of feelings. Applied \& Preventive Psychology, 4(3), 197-208. doi:10.1016/S0962-1849(05)80058-7.

[45] Mayer, J., \& Salovey, P. (1995). Emotional intelligence and the construction and regulation of feelings.Applied \& Preventive Psychology, 4(3), 197-208. doi:10.1016/S0962-1849(05)80058-7

[46] Mayer, J. \& Salovey, P. (1997). Emotional development and emotional intelligence. Cambridge University Press: New York.

[47] Mayer, J. D., \& Ciarrochi, J. (2006). Clarifying concepts related to emotional intelligence: A proposed glossary. In J. Ciarrochi, J. Forgas, \& J. D. Mayer (Eds). Emotional intelligence in everyday life (2nd ed). New York: Psychological Press.

[48] Mayer, J., Salovey, P., \& Caruso, D. (2004). Emotional intelligence: Theory, findings, and implications. Psychological Inquiry, 15(3), 197-215. doi:10.1207/s15327965pli1503_02.

[49] Mayer, J., Caruso, D., \& Salovey, P. (1999). Emotional intelligence meets traditional standards for an intelligence. Intelligence, 27(4), 267-298. doi:10.1016/S01602896(99)00016-1.

[50] Mayer, J. D., Perkins, D. M., Caruso, D. R., \& Salovey, P. (2001). Emotional intelligence and giftedness.Roeper Review, 23(3), 131137. doi:10.1080/02783190109554084.

[51] Mayer, J., Salovey, P., \& Caruso, D. (2000). Models of emotional intelligence. In R. Sternberg (Ed.), Handbook of intelligence. Cambridge, UK: Cambridge University Press.

[52] Mayer, J., \& Salovey, P. (1995). Emotional intelligence and the construction and regulation of feelings. Applied \& Preventive Psychology, 4(3), 197-208. doi:10.1016/S0962-1849(05)80058-7

[53] Mayer, J., \& Salovey, P. (1997). What is emotional intelligence? In P. Salovey \& D. J. Sluyter(Eds.), Emotional development and emotional intelligence (pp. 3-31). New York: Basic Books.

[54] Mayer, J., Salovey, P., Caruso, D., \& Sitarenios, G. (2003). Measuring emotional intelligence with MSCEIT V2.0. Emotion, 3, 97-105. DOI: 10.1037/1528-3542.3.1.97

[55] Mikolajczak, M., Petrides, K., \& Hurry, J. (2009, June). Adolescents choosing self-harm as an emotion regulation strategy: The protective role of trait emotional intelligence. British Journal of Clinical Psychology, 48(2), 181-193. Retrieved July 26, 2009, doi:10.1348/014466S08X386027.

[56] Natano, C. (2001). Emotional intelligence: its relationship to the decision-making styles among the tertiary school administrators in the Cotabato Area. Unpublished doctoral dissertation. Notre Dame University, Cotabato City, Philippines.

[57] Petrides, K. V., \& Furnham, A. (2000). Gender differences in measured and self-estimated trait emotional intelligence. Sex Roles, 42(5-6), 449-461. doi:10.1023/A:1007006523133.

[58] Petrides, K. V., Furnham, A., \& Mavroveli, S. (2007). Trait emotional intelligence: Moving forward in the field of EI. In G. Matthews, M. Zeidner, R. D. Roberts, G. Matthews, M. Zeidner, R. D. Roberts (Eds.) ,The science of emotional intelligence: Knowns and unknowns (pp. 151-166). New York, NY US: Oxford University Press. Retrieved from EBSCOhost.

[59] Posner, M. I. (2003). Imaging a science of mind. Trends in Cognitive $\quad$ Sciences, $\quad 7(10), \quad 450-453$. doi:10.1016/j.tics.2003.08.013.

[60] Rothbart, M., Ahadi, S., \& Evans, D. (2000). Temperament and personality: Origins and outcomes. Journal of Personality and Social Psychology, 78(1), 122-135. doi:10.1037/00223514.78.1.122.

[61] Rothbart, M. K., Ellis, L. K., \& Posner, M. I. (2011). Temperament and self-regulation. In K. D. Vohs, R. F. Baumeister, K. D. Vohs, \& R. F. Baumeister (Eds.), Handbook of self-regulation: Research, theory, and applications (2nd ed., pp. 441-460). New York, NY US: Guilford Press. Retrieved from EBSCOhost

[62] Saarni, C. (1999). The development of emotional competence. New York: Guilford Press.

[63] Salovey, P., Woolery, A., \& Mayer, J. (2002). Emotional intelligence: conceptualization and measurement. In. G.J.O. Fletcher, G. Fletcher, \& M.S. Clark (Eds.), Blackwell handbook in social psychology (pp. 279-307). Oxford, UK.Wiley-Blackwell. 
[64] Salovey, P. , \& Mayer, J. D. (1990). Emotional intelligence. Imagination, Cognition, and Personality, 9, 185-211.

[65] Salovey, P., Mayer, J., Goldman, S., Turvey, C., \& Palfai, T. (1995). Emotional attention, clarity, and repair: Exploring emotional intelligence using the Trait Meta-Mood Scale. Emotion, Disclosure, \& Health, 125-154. Washington, DC US: American Psychological Association. doi:10.1037/10182-006.

[66] Sta. Maria, L. (2007). Emotional intelligence: Its relationship to academic achievement. Unpublished master's thesis. Adventist University of the Philippines, Silang, Cavite.
[67] Urquijo, I., Extremera, N., \& Villa, A. (2016). Emotional intelligence, life satisfaction, and psychological well-being in graduates: The mediating effect of perceived stress. Applied research in quality of life, 11(4), 1241-1252.

[68] Zeidner, M., Matthews, G., Roberts, R., \& MacCann, C. (2003). Development of emotional intelligence: Towards a multi-level investment model. Human Development, 46(2-3), 69-96. doi:10.1159/000068580.

[69] Zeidner, M., Matthews, G., \& Roberts, R. (2009). What we know about emotional intelligence: How it affects learning, work, relationships, and our mental health. Cambridge, MIT Press. 